\title{
Preferential killing of human lung cancer cell lines with mitochondrial dysfunction by nonthermal dielectric barrier discharge plasma
}

\author{
K Panngom ${ }^{1,2}$, KY Baik ${ }^{\star, 2}$, MK Nam $^{3}, \mathrm{JH} \mathrm{Han}^{3}, \mathrm{H} \mathrm{Rhim}^{3}$ and EH Choi ${ }^{*, 1,2}$
}

The distinctive cellular and mitochondrial dysfunctions of two human lung cancer cell lines (H460 and HCC1588) from two human lung normal cell lines (MRC5 and L132) have been studied by dielectric barrier discharge (DBD) plasma treatment. This cytotoxicity is exposure time-dependent, which is strongly mediated by the large amount of $\mathrm{H}_{2} \mathrm{O}_{2}$ and $\mathrm{NO}_{\mathrm{x}}$ in culture media generated by DBD nonthermal plasma. It is found that the cell number of lung cancer cells has been reduced more than that of the lung normal cells. The mitochondrial vulnerability to reactive species in H460 may induce distinctively selective responses. Differential mitochondrial membrane potential decrease, mitochondrial enzymatic dysfunction, and mitochondrial morphological alteration are exhibited in two cell lines. These results suggest the nonthermal plasma treatment as an efficacious modality in lung cancer therapy.

Cell Death and Disease (2013) 4, e642; doi:10.1038/cddis.2013.168; published online 23 May 2013

Subject Category: Cancer

One of the most important questions in cancer therapy is the selective killing of cancer cells without damaging normal cells. Generally, cancer cells are known to generate more reactive oxygen species (ROS) and be more damaged by exogenous ROS. ${ }^{1}$ Therefore, researchers have searched ROS generating drugs for preferential cytotoxicity in cancer cells. ${ }^{2,3}$ In that sense, the nonthermal plasma had been introduced as a tool with a potential of shifting current paradigm of cancer treatment. ${ }^{4}$ Nonthermal plasma generates various reactive species including ultraviolet, charges, and reactive nitrogen species as well as ROS in cell culture media. ${ }^{5-7}$

The biomedical application of nonthermal plasma is emerging field. Its potential has been demonstrated in various applications such as sterilization of infected tissues, acceleration of wound healing, induction of blood coagulation, delicate surgery, and so on. ${ }^{5}$ Among these, the most intensively studied one may be its application to anticancer therapeutics. ${ }^{8}$ Reactive species generated from nonthermal plasma has successfully induced apoptosis through DNA damage and mitochondrial dysfunction in cancer cell lines. $^{8-11}$ Moreover, a few previous studies demonstrated selective plasma-induced easy detachment of cancer cells to normal cells. ${ }^{4,12}$ However, there is still no report comparing the nonthermal plasma-induced cytotoxicity in cells from the same organ. As cancer cells from different organs have differential responses to the same plasma stimuli, ${ }^{13}$ cells originated from same organ should be used for sounding out the potential of plasma cancer therapy.
In this experiment, we examined a cancer cell line $\mathrm{H} 460$ and normal cell lines MRC5 and L132 from human lung. Lung cancer is the most lethal cancer, which is a leading cause of human death in both men and women. ${ }^{3,14}$ Among two types of lung cancer cells, non-small cell lung cancer kills people $>85 \%$ and has very complex causes. ${ }^{3,15}$ Importantly, lung cancers have propensity to metastasize early, ${ }^{14}$ have drug resistance and poor target specificity, ${ }^{3}$ and frequently overexpress antiapoptotic protein, such as $\mathrm{bcl}-\mathrm{xL}^{16}$ and survivin. ${ }^{14}$ Therefore, it is worth to try new modality in highly challenging lung cancer therapy, and the nonthermal plasma can be a strong candidate as Kim et al. ${ }^{17}$ showed in precise micro-plasma jet device.

Herein, we present the preferential killing of lung cancer cells to lung normal cells by nonthermal DBD plasma treatment. This differential sensitivity is shown to be strongly related to the mitochondrial dysfunctions, such as morphological changes, reduction in mitochondrial metabolic activity, and reduction in mitochondrial membrane potential (MMP). This first report of preferential killing of human lung cancer cells possibly opens new lung cancer therapy by using nonthermal plasma.

\section{Results}

The amount of $\mathrm{H}_{2} \mathrm{O}_{2}$ and $\mathrm{NO}_{x}$ in culture media. Figure 1a is a schematic diagram of dielectric barrier discharge (DBD) plasma device used in this experiment. The DBD plasma consists of upper electrode made from silver and lower

\footnotetext{
${ }^{1}$ Department of Plasma Bioscience and Display, Kwangwoon University, Seoul, Republic of Korea; ${ }^{2}$ Plasma Bioscience Research Center, Kwangwoon University, Seoul, Republic of Korea and ${ }^{3}$ Department of Biomedical Sciences, The Catholic University of Korea, Seoul, Republic of Korea

*Corresponding author: EH Choi or KY Baik, Department of Plasma Bioscience and Display, Kwangwoon University, 447-1, Wallgye-dong, Nowon-Gu, Seoul 139-701, Republic of Korea. E-mail: ehchoi@kw.ac.kr or kybaik@kw.ac.kr

Keywords: nonthermal DBD plasma; human lung cancer cell lines; mitochondrial dysfunction; apoptosis

Abbreviations: DBD, dielectric barrier discharge; ROS, reactive oxygen species; MMP, mitochondrial membrane potential

Received 07.2.13; revised 30.3.13; accepted 03.4.13; Edited by A Stephanou
} 
a
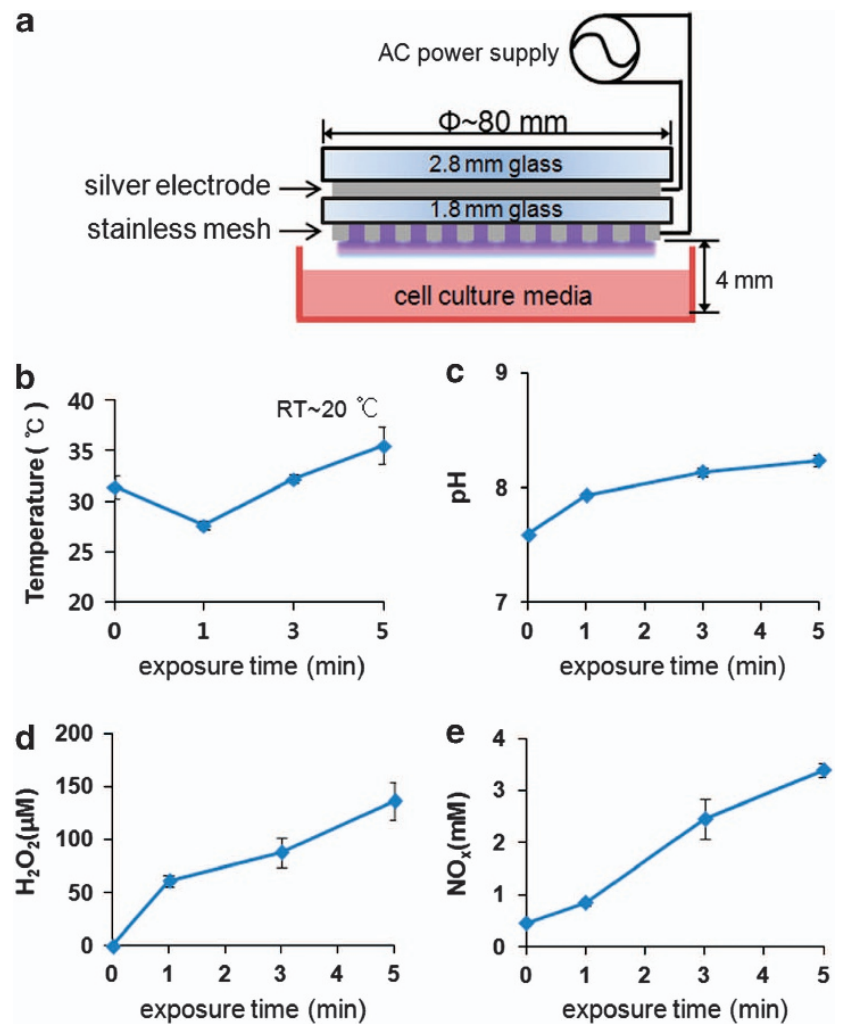

Figure 1 Schematic diagram of DBD plasma device and its time-dependent effects on cell culture media. (a) The device consists of silver electrode, dielectric glass, and stainless steel mesh electrode. The distance between DBD device and cell culture plate is $\sim 4 \mathrm{~mm}$. (b) The temperature of DBD plasma device reaches up to $35.5^{\circ} \mathrm{C}$ after $5 \mathrm{~min}$ exposure. (c) The $\mathrm{pH}$ of DMEM media increases 0.8 after 5 min exposure. (d) $\mathrm{H}_{2} \mathrm{O}_{2}(136 \mathrm{Mm})$ is generated after 5 min exposure. (e) $\mathrm{NO}_{x}$ (3.4 mM) is generated after $5 \mathrm{~min}$ exposure

electrode made from stainless steel mesh. The interspacing distance between meshes is about $2 \mathrm{~mm}$. The electrical power of $5.7 \mathrm{~W}$ has been supplied to the upper and lower electrodes to generate the atmospheric pressure nonthermal plasma. Here the airborne radicals from the plasma have been supplied to the cell culture media. During plasma exposure for $5 \mathrm{~min}$, the temperature of media raised up to $35.5^{\circ} \mathrm{C}$ (Figure $1 \mathrm{~b}$ ) and the $\mathrm{pH}$ of media increased up to 8.2 (Figure 1c). Although we do not use air blowing into cell culture media, our DBD plasma device can generate significant amount of $\mathrm{H}_{2} \mathrm{O}_{2}$ and $\mathrm{NO}_{x}$ in media. Figures $1 \mathrm{~d}$ and $e$ showed the amount of $\mathrm{H}_{2} \mathrm{O}_{2}$ and $\mathrm{NO}_{x}$ in cell culture media after plasma treatment. The amount of $\mathrm{H}_{2} \mathrm{O}_{2}$ increased to $61.28,87.61$ and $136.11 \mu \mathrm{M}$, following 1,3 and 5 min exposure, respectively. The $\mathrm{NO}_{x}$ quantity increased to $0.85,2.46$ and $3.39 \mathrm{mM}$ for 1,3 and $5 \mathrm{~min}$ exposure, respectively. The amount of $\mathrm{H}_{2} \mathrm{O}_{2}$ and $\mathrm{NO}_{x}$ depend on the plasma treatment time, which should be related to time-dependent toxic effects of plasma treatment on cells.

Cell number. Figure 2a shows typical phase contrast microscopic images of cells after $24 \mathrm{~h}$ from the nonthermal DBD plasma exposure. The decrease of cell number with exposure time is clearly shown in all cell lines. Most $\mathrm{H} 460$ cancer cells after $5 \mathrm{~min}$ exposure even failed to attach on the surface and became dead. For quantitative comparison, we counted cell numbers by using hemocytometer during 3 days' incubation, and the number ratio to every day control was plotted in Figure $2 \mathrm{~b}$. The cell number ratio was significantly decreased even in 1-min plasma-treated $\mathrm{H} 460$ cancer cells $(P<0.01)$, but it was not significant in MRC5 and L132 normal cells $(P>0.05)$. Moreover, the relative cell number to control is significantly decreasing following incubation day in $\mathrm{H} 460$, which can be expected from the reduced colony size of $\mathrm{H} 460$ in Figure $2 \mathrm{a}$ and also the cell cycle arrest in $\mathrm{G}_{2} / \mathrm{M}$ state as shown in Figure $\mathrm{S} 2$ (supporting information). Figure 2c shows comparison of survival rate among two lung cancer cell lines (H460 and HCC1588) and two lung normal cell lines (MRC5 and L132) after 1 min plasma exposure. Normal cell lines have survived more than cancer cell lines under $1 \mathrm{~min}$ plasma exposure. Although longer time exposure induced more cell death in all cell lines, normal cells should have higher durability to plasma treatment.

Cellular and mitochondrial morphology. The surviving cells after plasma exposure adhered to the surface with slightly different morphology as shown in Figures $3 a$ and c. The plasma-treated $\mathrm{H} 460$ showed bumpy boundary and localized focal adhesions, and the plasma-treated MRC5 showed wider adhesion with losing their initial spindle shape. The enlarged images show that actin fibers became shortened and localized near membrane in $\mathrm{H} 460$, and actin fibers were reorganized following their widen morphology in MRC5 (Supplementary Figure S3, supporting information).

At the same time, plasma treatment induced morphological changes of mitochondria in both $\mathrm{H} 460$ and MRC5 as shown in Figures $3 \mathrm{~b}$ and $\mathrm{d}$. In plasma-exposed cells for $<3 \mathrm{~min}$, mitochondria are rod-shaped and form tubular networks around nucleus. However, 5 min plasma-exposed cells show swollen or fragmented mitochondria. Moreover, it is notable that the mitochondria in 5 min plasma-treated $\mathrm{H} 460$ became giants and mitochondria in MRC5 became smaller, which should come from improper fusion and uncontrolled fission, respectively. These morphological changes in mitochondria and cytoskeletons strongly support that the cell death induced by DBD nonthermal plasma should not be mediated by necrosis. ${ }^{18,19}$

Apoptosis. To check whether cell death induced by plasma is apoptosis, we stained cells with Annexin V, an early apoptotic indicator. In Figure 4a, enhanced fluorescent intensity of Annexin $V$ shows the increase of apoptosis ratio in plasma-treated cells in both cell lines. Besides, we found that the apoptosis ratio depends on cell type as well as plasma exposure time. Among two cells, H460 showed a higher intensity of Annexin $\mathrm{V}$ at any plasma exposure time. In addition, when we stained them with propidium iodide $(\mathrm{PI})$ dye together, we found that $\mathrm{H} 460$ undergoes apoptosis at a faster rate than MRC5 (Supplementary Figure S4, supporting information). When many $\mathrm{H} 460$ cells were stained by both Annexin $\mathrm{V}$ and $\mathrm{PI}$ dyes under $\mathrm{H}_{2} \mathrm{O}_{2}$ stimulus, MRC5 cells were stained only by Annexin $\mathrm{V}$ under the same $\mathrm{H}_{2} \mathrm{O}_{2}$ stress. H460 cells showed higher late apoptosis rate under plasma treatment as well, which is consistent with higher cell death 
a
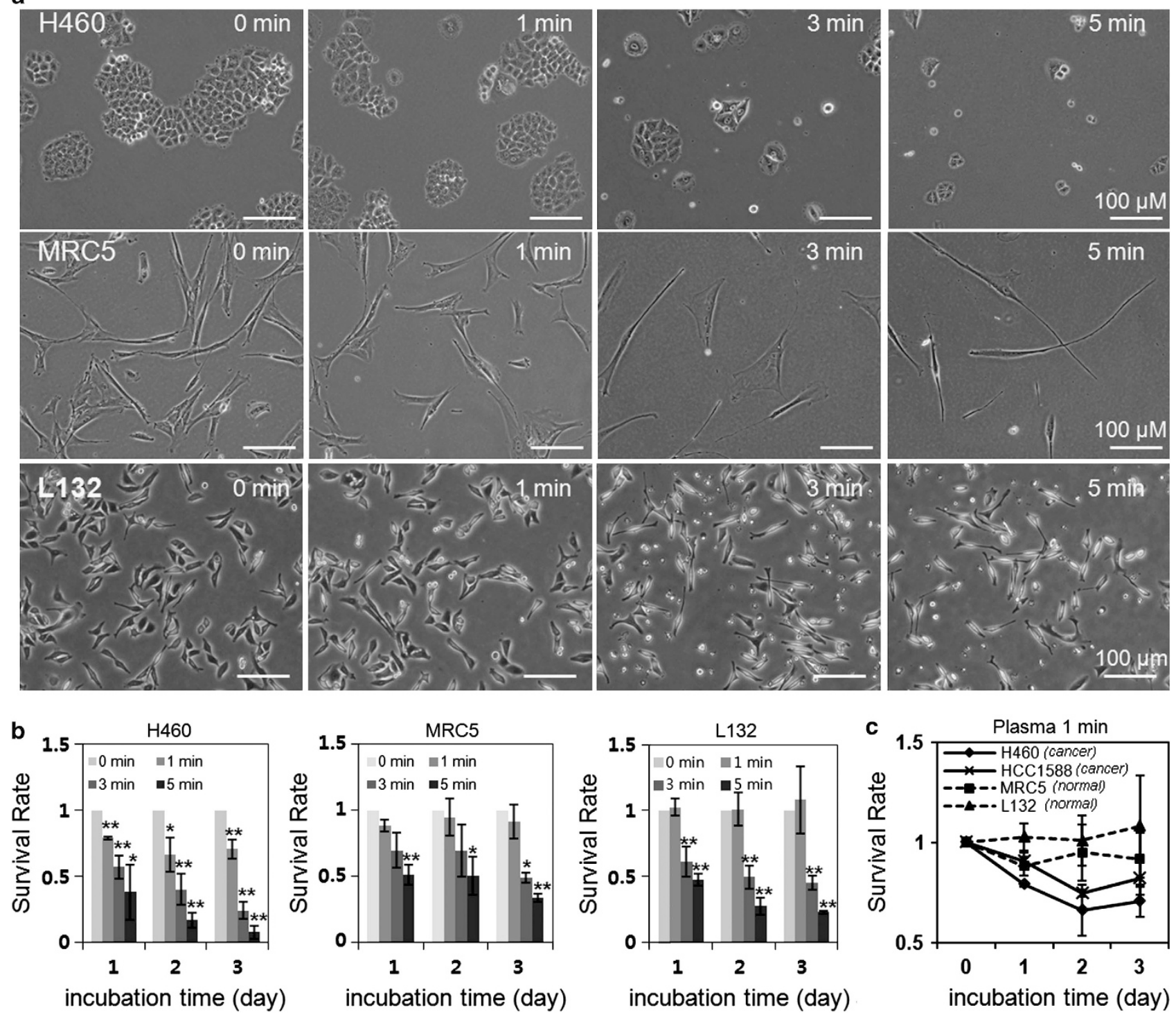

Figure 2 DBD plasma effects on cell death of lung cancer cells (H460 and HCC1588) and lung normal cells (MRC5 and L132). (a) The bright field images of H460, MRC5, and L132 at 1 day after plasma exposure. All scale bars are $100 \mu \mathrm{m}$. (b) The relative cell numbers to control showed exposure time-dependent and incubation time-dependent death rate. $\mathrm{H} 460$ showed more severe lethality than MRC5 and L132 by nonthermal DBD plasma treatment. (c) Survival rate of two lung cancer cell lines and two lung normal cell lines after 1 min plasma treatment was compared during 3 days' incubation. Students' $t$-test was performed to control ( ${ }^{*}$ denotes $\mathrm{P}<0.05$ and ${ }^{* *}$ denotes $\mathrm{P}<0.01$ )

rate. However, we found that the lung normal cell MRC5 became smaller until 3 min plasma exposure, but became bigger in cell size after 5 min plasma treatment. As shown in the flow cytometry data in Figure $4 b$, both cell lines undergo time-dependent apoptotic process. It is found that the higher and faster apoptosis rate is shown in H460 cancer cells in comparison with L132 normal cells. The cell population at lower right part (Annexin V-PE-positive and 7-AAD-negative) representing the cells undergoing early apoptosis and upper right part (Annexin V-PE-positive and 7-AAD-positive) representing the cells undergoing late apoptosis of already dead cells have increased with time-dependent manner and it is shown to be much faster in $\mathrm{H} 460$.

Mitochondrial enzyme activity and ATP generation. In order to examine the distinctive nonthermal plasma effects on mitochondria that has important roles in apoptosis, we measured MTS reduction and ATP generation in $\mathrm{H} 460$ and MRC5. MTS reduction is mainly attributed to mitochondrial enzymes and electron carriers, ${ }^{20}$ which indicates the mitochondrial respiratory activity. Their final product ATP was quantified by luciferase in galactose-containing cell culture media. ${ }^{21}$ Galactose was used instead of glucose to exclude the ATP generation through glycolysis in cytoplasm in cancer cells. ${ }^{22,23}$ Interestingly, plasma induced significant changes in MTS reduction and ATP production with almost exactly same tendency (Figures $5 \mathrm{a}$ and $\mathrm{b}$ ). Both relative values reduced more with plasma exposure time increase at day 1. The effect of 1-min-plasma exposure was almost negligible; however, longer plasma exposure (3 and $5 \mathrm{~min}$ exposure) induced significant reduction in mitochondrial enzyme activity as well as mitochondrial malfunction, 
a
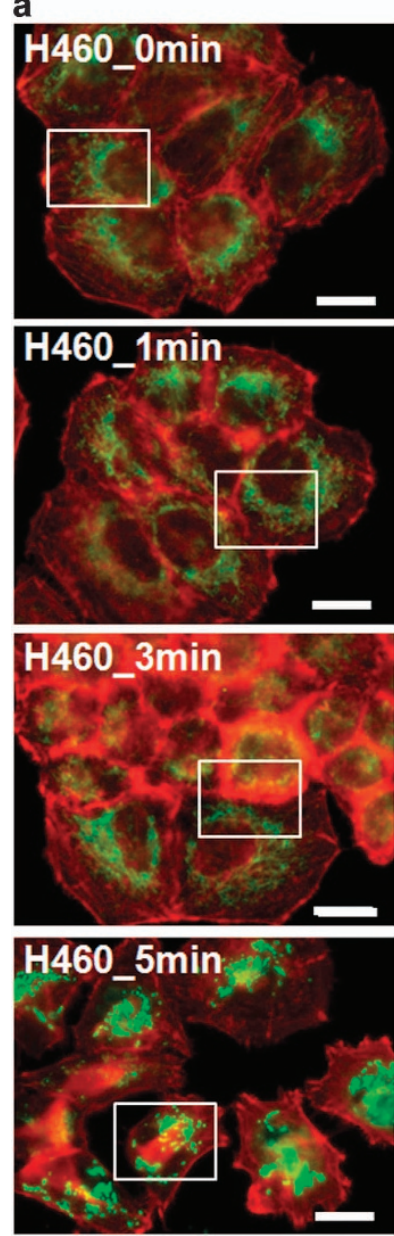

b
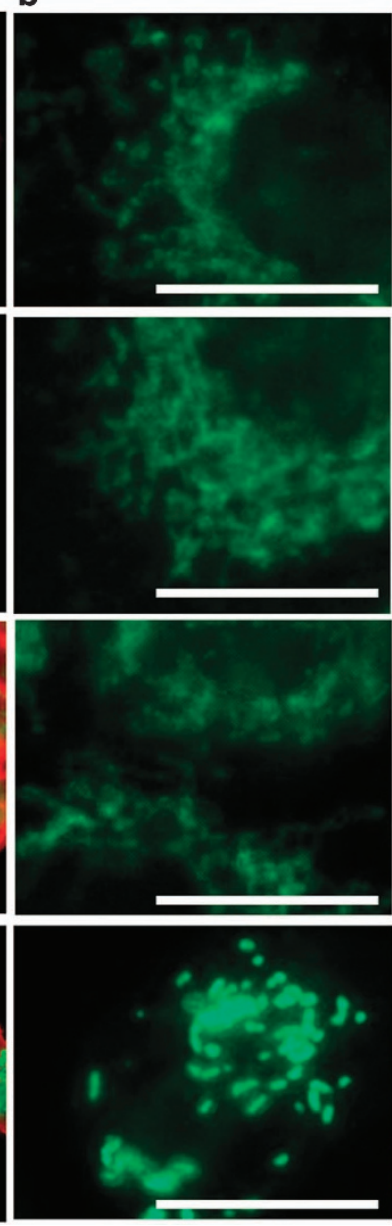

C
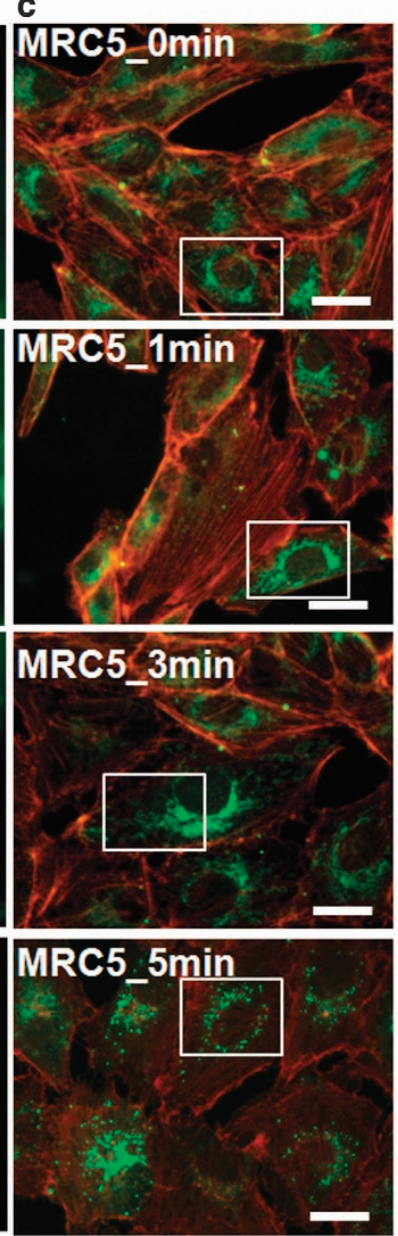

d
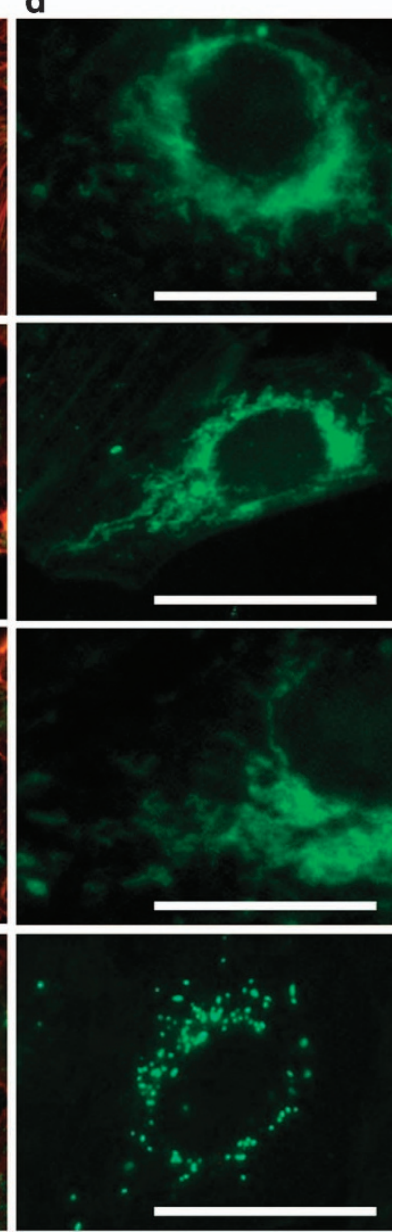

Figure 3 Fluorescence images of actin- (red) and mitochondria (green)-stained (a and $\mathbf{b}) \mathrm{H} 460$ and (c and $\mathbf{d})$ MRC5 cell lines. Actin staining shows the morphological changes of bumpy boundary in $\mathrm{H} 460$ and of wider adhesion in MRC5. Mitochondria become fragmented after 5 min plasma exposure in both cell lines. Scale bars are $10 \mu \mathrm{m}$

especially in $\mathrm{H} 460$. These reductions in mitochondrial respiration show similar tendency to the increase of Annexin V-positive apoptosis.

Mitochondrial membrane potential. MMP is known to be strongly related to mitochondrial potential. To determine $\operatorname{MMP}\left(\Delta \psi_{\mathrm{m}}\right)$ change, we stained two cell lines with a lipophilic cationic dye JC-1, which aggregates in inner mitochondrial membrane to exhibit red fluorescence in normal polarized mitochondria and green fluorescence in depolarized mitochondrial membrane. ${ }^{11}$ For positive MMP depolarization, we used a proton ionophore Carbonyl cyanide 3-chlorophenylhydrazone (cccp), which destroys the MMP quickly. Figure 6 is a graph of cell number distribution by green fluorescence intensity, representing mitochondrial membrane depolarization after plasma treatment in lung cancer cell H460 and lung normal cell MRC5. The green intensity increased (MMP decreases) following plasma exposure time in both cell lines; however, MMP of lung cancer cells decreased more to the level of MMP of cccp-treated positive cells. To quantify the relative change of MMP, we made the difference of green fluorescence intensity between negative control $(0 \%)$ and cccp-treated positive control (100\%), and the calculated relative intensity change was plotted in Figure $6 \mathrm{c}$. The graph shows $>50 \%$ reduction in MMP $(50 \%$ increase in $\mathrm{JC}-1$ fluorescence) in $\mathrm{H} 460$ when they were treated with nonthermal DBD plasma for $1 \mathrm{~min}$. Nonthermal plasma may be very effective to reduce MMP, because plasma treatment generates charged particles that can interrupt membrane polarity.

Moreover, we observed the mitochondrial ultrastructure change that is related to the MMP decreasing (Supplementary Figure S5, supporting information). In control cells, the mitochondrial ultrastructure showed various shape (elongate and circular) and size with clear cristae under transmission electron microscope observation. ${ }^{24,25}$ There happened significant damages on mitochondrial cristae in case of 5 min plasma-exposed $\mathrm{H} 460$, which may come from mitochondrial swelling, as shown in Figure 3. Structural change of mitochondrial cristae in MRC5 seemed little in TEM images, although they showed fragmentation in fluorescence microscope, as shown in Figure 3d.

\section{Discussion}

Selective killing of lung cancer cells by nonthermal plasma. Our study demonstrated that the nonthermal DBD plasma could induce high cell death in lung cancer cells. 
a

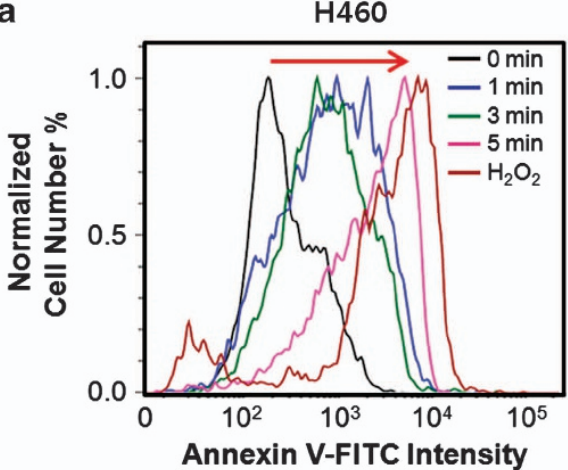

b
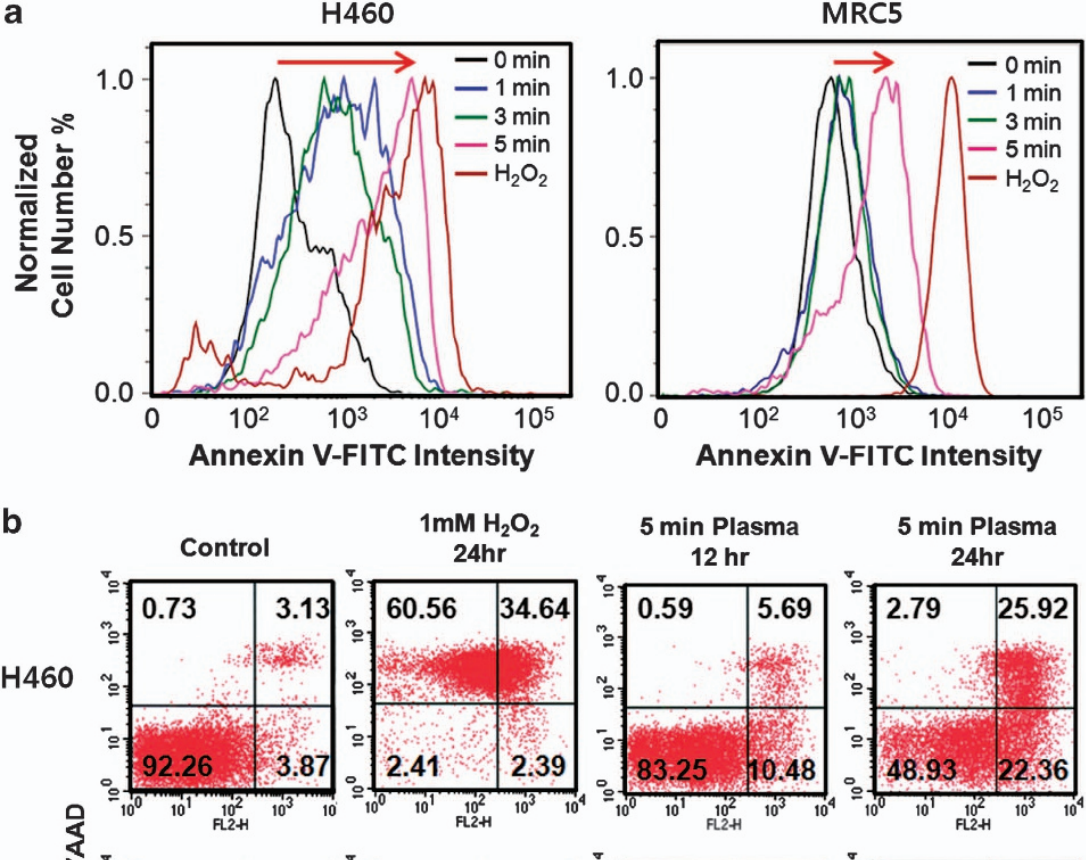

Annexin V-FITC Intensity
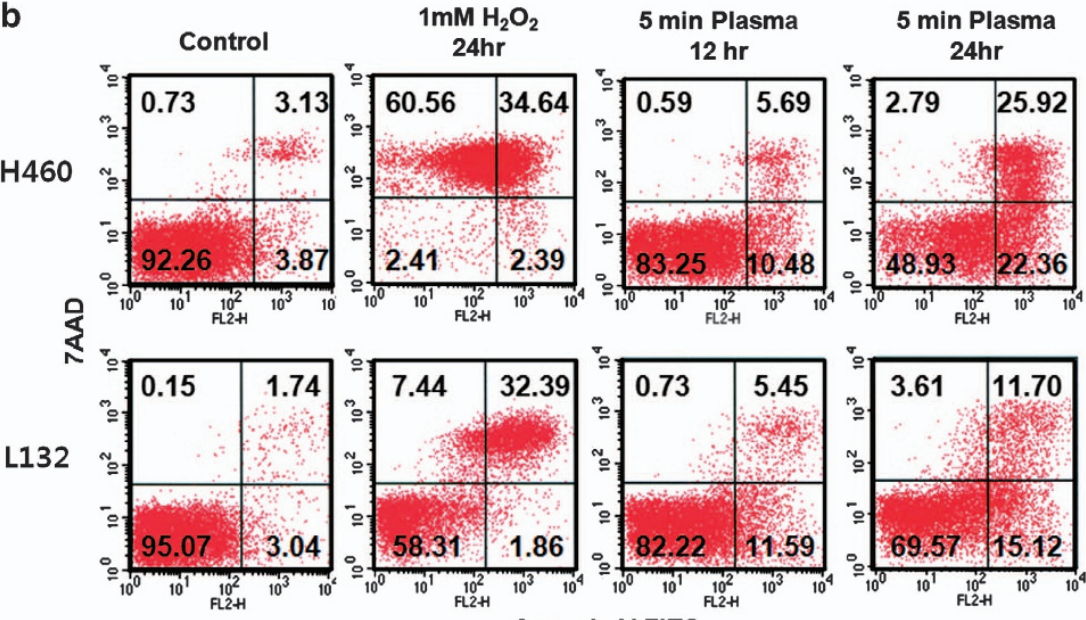

Figure 4 The flow cytometry data of Annexin $V$ and $7 A A D$ staining of lung cells after plasma treatment. (a) The normalized cell number distribution to Annexin $V$ intensity of $\mathrm{H} 460$ and MRC5 was plotted by plasma exposure time. $\mathrm{H}_{2} \mathrm{O}_{2}(1 \mathrm{mM})$ was used to make positive control. (b) Apoptosis of $\mathrm{H} 460$ and $\mathrm{L} 132$ cells was evaluated after 12 and $24 \mathrm{~h}$ incubation from nonthermal plasma treatment for $5 \mathrm{~min}$. The number represents the percentage of cells in each quadruple

These phenomena can be understood by the generation of highly reactive radicals from the device. Plasma generated from atmospheric air contains radicals mainly from $\mathrm{N}_{2}$ and $\mathrm{O}_{2}$, which contains $\mathrm{N}, \mathrm{O}, \mathrm{O}_{3}, \mathrm{NO}, \mathrm{NO}_{2}, \mathrm{OH}$, and so on. The final products of these unstable species in liquid might be $\mathrm{H}_{2} \mathrm{O}_{2}$ and $\mathrm{NO}_{x}$, which are quite stable. Although it is not clear what component of the nonthermal DBD plasma has a main role in these toxicity, we can point out that this dose-dependent toxicity have same tendency with the amount of $\mathrm{H}_{2} \mathrm{O}_{2}$ and $\mathrm{NO}_{x}$ melted in liquid as previous reports. $^{26}$ Direct generation of various kinds of ROS in culture media by nonthermal plasma has been known to increase intracellular ROS level linearly. ${ }^{6,27}$ Considering the strong cell line dependency in chemically induced endogenous ROS generation, this direct ROS generation can be generally good strategy in cancer therapy $(A)$. Kalghatgi et al. $^{6}$ Hoentsch et $a .^{13}$ and Panngom et al. ${ }^{28}$ reported that the cell culture media mediates the plasma effect on cell death and cell adhesion because of the interaction of plasma with organic components of cell culture media. The nonthermal DBD plasma might generate oxidative potential in cell culture media, which induced higher cell death in lung cancer cell lines than that in lung normal cell lines.

The main point in plasma cancer therapy should be the control of ROS dose for maximal cancer selectivity. In this experiment, the survival rate of two lung cancer cells showed almost linear decrease following plasma exposure time. However, the survival rates of normal cells started to decrease after $1 \mathrm{~min}$ exposure. With higher plasma dose with longer time exposure, the survival rate of HCC1588 lung cancer cells was not significantly lower than L132 lung normal cells. This result implies that plasma power should be delicately controlled for selective cancer cell killing. Measuring the endogenous ROS level and antioxidant defense capacity might be necessary for decision.

Nonthermal plasma-induced apoptosis through mitochondrial damage. The cell death induced by nonthermal plasma was not necrotic but apoptotic. The population of Annexin V-stained cells and the population of $\mathrm{PI}$-stained cells increased with increasing exposure time and incubation time, as shown in Figure 4. The percentage of apoptotic cells $(\mathrm{H} 460)$ was $16 \%$ at $12 \mathrm{~h}$ and $48 \%$ at $24 \mathrm{~h}$ after $5 \mathrm{~min}$ plasma exposure. The percentage of late apoptosis also increased from 6 to $26 \%$ during $12 \mathrm{~h}$. Normal cells showed similar tendency with lower apoptotic ratio $(28 \%$ in L132 and $15 \%$ in MRC5). This time-dependent cell death implies that the cell death induced by nonthermal plasma treatment was not necrotic. The apoptosis is a complex process that included at least two main processes consisting 

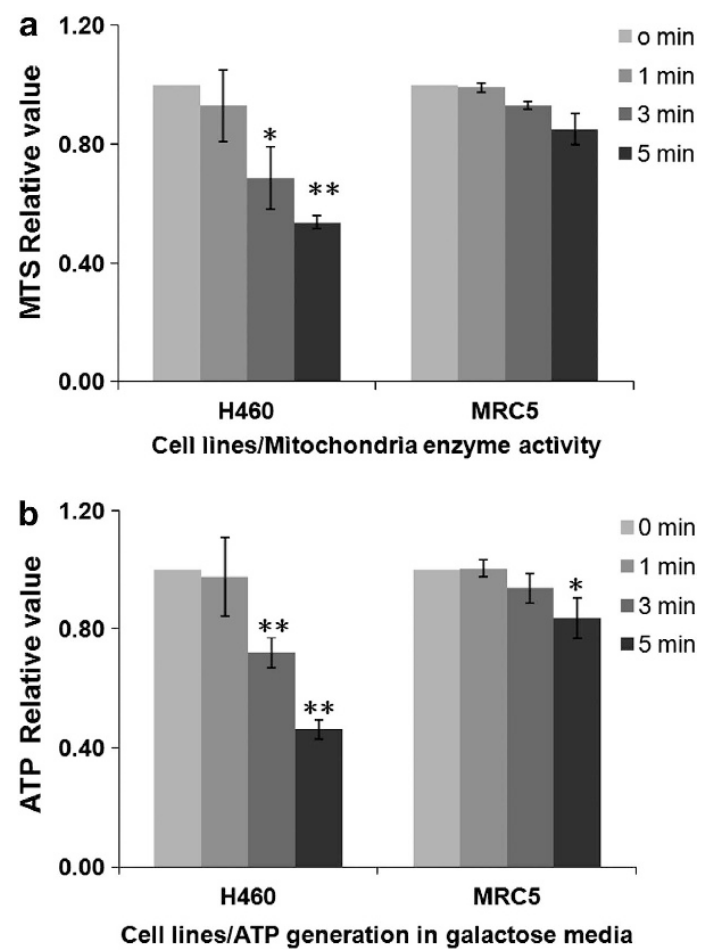

Figure 5 DBD plasma effects on mitochondrial metabolic activity of $\mathrm{H} 460$ and MRC5 after $24 \mathrm{~h}$ from treatment. (a) The relative MTS value of $\mathrm{H} 460$ and MRC5, and (b) the relative ATP value of $\mathrm{H} 460$ and MRC5 in galactose media. $\mathrm{H} 460$ showed much decreased mitochondrial enzymatic activity with plasma exposure time in both assays. Students' $t$-test was performed to control $\left({ }^{*}\right.$ denotes $P<0.05$ and ${ }^{* *}$ denotes $P<0.01$ )

of the extrinsic pathway and the intrinsic pathway. ${ }^{29}$ Death receptors have a key role in mediating external signals to caspase8 in extrinsic pathway, and the mitochondria has a main role in deciding a cell fate in intrinsic pathway. ${ }^{30}$ In our previous study, we showed upregulated mRNA expression of both Caspase8 and Bax genes in $\mathrm{H} 460$ under plasma treatment, which implies the activation of both extrinsic and intrinsic pathways. ${ }^{13} \mathrm{Bax}$ is a $\mathrm{Bcl}-2$ family, which is related to signaling of mitochondrial membrane in the process of early apoptosis. ${ }^{29}$

The nonthermal plasma-induced cell death may be strongly related to mitochondrial damages, especially in cancer cells. The nonthermal plasma reduced the mitochondrial enzyme activity and respiration rate, which significantly occurred in cancer cells with 3 and $5 \mathrm{~min}$ exposure. Moreover, it reduced the MMP significantly from 1 min exposure in cancer cells. The reduction of MMP is early prerequisite step toward apoptosis. ${ }^{11,31,32}$ The mitochondrial morphological change was also observed in $5 \mathrm{~min}$ plasma-treated cells, which is generally considered as unbalance between fission and fusion. There happened significant damages on mitochondrial cristae in the case of 5-min plasma exposure, which may come from mitochondrial swelling. According to the experiment of Gottlieb et al..$^{32}$ mitochondrial swelling comes as a consequence of MMP decrease and permeability increase. ${ }^{31}$ This time-dependent differential phenomena in mitochondria may be understood as the sequence of events under ROS stress. MMP of cancer cells was reduced easily with small
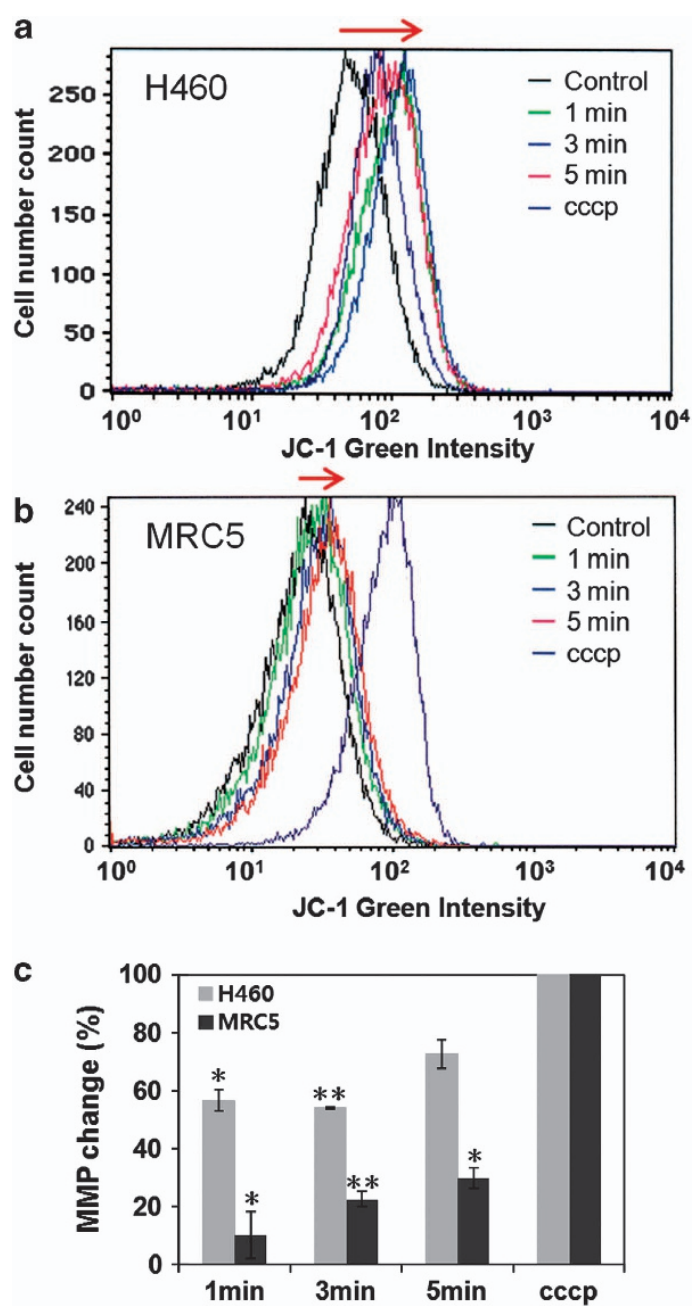

Figure 6 The flow cytometry data of normalized cell number distribution in JC-1 green fluorescence intensity of (a) $\mathrm{H} 460$ and (b) MRC5 after plasma treatment. (c) The relative number value of JC-1 green fluorescence to control. The MMP of plasma-treated $\mathrm{H} 460$ decreased nearer to the cccp-treated value than MRC5 $(n=3)$. Students' $t$-test was performed to control $\left({ }^{*}\right.$ denotes $P<0.05$ and ** denotes $P<0.01$ )

dose of ROS generated by nonthermal plasma, which might induce following events such as reduction in enzymatic activity, reduction in respiration rate, and unbalance in their morphological dynamics. In case of normal cells, however, the mitochondrial damage was not so severe with higher plasma dose. This differential mitochondrial response may be attributed to the higher respiration rate of cancer cells. ${ }^{2}$

On the basis of these mitochondrial severe damages, we can mention that targeting mitochondria is a good strategy in lung cancer therapy, and nonthermal DBD plasma treatment can be a good modality. According to previous reports, the mitochondrial targeting efficiency can be improved with drugs or genetic molecules. ${ }^{21}$ However, there should be delicate environmental control, because the mitochondrial enzyme activity was found to be very sensitive to nutritional supplements. ${ }^{33,34}$ Besides, the morphological abnormality of surviving normal cells after plasma treatment should be 
considered, which is an important large-scale manifestation of the physiological state of cells. ${ }^{35-37}$ The physiological states of surviving normal cells and the underlying mechanisms should be studied to reduce unexpected side effects of plasma medicine.

In conclusion, we showed higher apoptotic cell death in lung cancer cell line $\mathrm{H} 460$ than that in lung normal cell lines MRC5 by the nonthermal DBD plasma treatment, in which mitochondrial dysfunction has an important role. The nonthermal DBD plasma treatment induced MMP decrease, mitochondrial enzymatic dysfunction, and mitochondrial morphological alteration in sequence. For therapeutic applications, the differential cellular responses to plasma treatment should be screened further according to cell morphology and cancer genotype. However, our results take the first step toward preferential killing of lung cancer cells by using the nonthermal DBD plasma treatment in lung cancer therapy.

\section{Materials and Methods}

Nonthermal DBD Plasma device. The DBD plasma consists of upper electrode made from silver and lower electrode made from stainless steel mesh. The device contained a 2.8-mm-thick upper glass and 1.8-mm-thick lower glass for dielectric substance, which was covered by stainless steel mesh. The diameter of DBD plasma area was about $80 \mathrm{~mm}$. For AC power supply, commercial transformers for neon light operate at $60 \mathrm{~Hz}$ were used. The input voltage was about $80 \mathrm{~V}$ (breakdown voltage $600 \mathrm{~V}$ and breakdown electric current $0.01 \mathrm{~A}$ in r.m.s.) and the power was $5.7 \mathrm{~W}$.

Cell culture and plasma treatment. Lung cancer cell lines (H460; human large-cell lung carcinoma cells and HCC1588; human squamous-cell lung carcinoma cells) and lung normal cell lines (MRC5; human fetal lung fibroblast cells and L132; human embryonic pulmonary epithelial cells) were purchased from Korean Cell Line Bank (Seoul, Korea). Cells were maintained in high glucose DMEM (SH30243.01, Hyclone, Logan, UT, USA) supplemented with 10\% FBS (SH30979.03, Hyclone), $1 \%$ of penicillin/streptomycin (15140, Gibco, Grand Island, NY, USA) and cells were grown on incubator containing $5 \%$ of $\mathrm{CO}_{2}$ at $37^{\circ} \mathrm{C}$. For plasma exposure, we used $5 \mathrm{ml}$ of cell suspension with concentration of $1 \times 10^{5}$ cells $/ \mathrm{ml}$ on the petridish (diameter $9 \mathrm{~cm}, 10090$, SPL, Pocheon-Si, Gyeonggi-do, Korea). The depth of media was about $0.8 \mathrm{~mm}$, and we kept the distance between the plasma device and the bottom of petridish $\sim 4 \mathrm{~mm}$. After plasma exposure, cell suspension was divided into 96-well tissue culture test plate (30096, SPL; $1 \times 10^{3}$ cells per well) for cell number counting and mitochondrial enzyme activity. For flow cytometry analysis, cells were incubated on the cell culture dish (20100, SPL) for $24 \mathrm{~h}$ without dividing, and cells for image analysis were incubated on cover glasses for $24 \mathrm{~h}$. Although both cell lines are adherent cells, plasma treatment in cell suspension state gives a little more stress than plasma treatment in adhesion state (Supplementary Figure S1, supporting information). Moreover, plasma exposure in both states induces similar time-dependent death rate.

Hydrogen peroxide $\left(\mathrm{H}_{2} \mathrm{O}_{2}\right)$ and nitric oxide $\left(\mathrm{NO}_{\mathrm{x}}\right)$ in media measurement. Amplex Red Hydrogen Peroxide Kit
(Molecular Probes, Invitrogen, Eugene, OR, USA) was used to measure the amount of $\mathrm{H}_{2} \mathrm{O}_{2}$ generated in media by DBD plasma. We added $50 \mu \mathrm{l}$ of standard curve samples, controls, and experimental samples to the 96-well plates with the $50-\mu \mathrm{l}$ Amplex Red reagent containing horseradish peroxidase solution. We incubated the plates for $30 \mathrm{~min}$ at room temperature in dark condition and detected fluorescence (ex.530/em.590) by fluorometer (Synergy HT, Biotek, Winooski, VT, USA).

$\mathrm{NO}_{x}$ was measured by using Nitric Oxide Colorimetric Assay kit (K262-200, Biovision, Milpitas, CA, USA). Nitrate reductase converted nitrate to nitrite, and Griess reaction was used to detect nitrate inside media. All steps of detection was performed according to the manufacturer's instructions. The absorbance was measured at $540 \mathrm{~nm}$ by spectrophotometer (Synergy HT, Biotek).

Cell number counting and mitochondrial metabolic activity assays. Cells were harvested from 96-well plates at 24,48 , and $72 \mathrm{~h}$ from plasma treatment, and the cell number was counted by using hemocytometer under light microscope (Ti-U, Nikon, Tokyo, Japan). At the same time, the mitochondrial enzyme activity was measured by MTS (CellTiter 96 Aqueous Non-Radioactive Cell Proliferation Assay, Promega, Madison, WI, USA) assay. Fifty microlitres of MTS solution in DMEM (the ratio $1: 5$ ) was added into 96well plate and the absorbance was measured at $490 \mathrm{~nm}$ after $2 \mathrm{~h}$ incubation by using spectrophotometer (Synergy HT, Biotek). The amount of ATP generated in both cell lines was measured at $24 \mathrm{~h}$ from plasma treatment. Cells were harvested, and same number of cells $\left(2 \times 10^{3}\right.$ cells per well) were seeded in white-walled 96-well assay plate (3610, Corning Inc, Corning, NY, USA). Following the manufacturer's instruction of Mitochondrial ToxGlo Assay (Promega), the amount of ATP was measured by luminescence using a plate reader (Synergy HT, Biotek). $\operatorname{cccp}(0.05 \mathrm{mM})$ was used for positive control.

Cellular and mitochondrial morphology. Actin fibers and mitochondria were stained after $24 \mathrm{~h}$ of plasma treatment. Cells on cover glass were washed with DPBS (WelGene, Daegu, Korea), fixed with $4 \%$ (v/v) paraformalaldehyde (15713, Electron Microscopy Sciences, Hatfield, PA, USA) for $15 \mathrm{~min}$, and permeabilized by $0.1 \%(\mathrm{v} / \mathrm{v})$ Triton $\mathrm{X}-100$ (T8532, Sigma, St. Louis, MO, USA) in PBS for $20 \mathrm{~min}$ at room temperature. After washing with PBS three times, actin fibers were stained by phalloidin dye ( 5 units $/ \mathrm{ml}$, Phallotoxins, Invitrogen) for $30 \mathrm{~min}$ at room temperature. After washing with PBS three times, mitochondria were stained by MitoTracker dye solution (200 nM, MitoTracker Mitochondrion-Selective Probes, Invitrogen). Samples were mounted with $50 \%(\mathrm{v} / \mathrm{v})$ glycerol and observed under $\times 40$ magnification of light and fluorescence microscope (Ti-U, Nikon).

Apoptosis detection. EzWay Annexin V-FITC apoptosis detection kit (Komabiotech, Inc, Seoul, Korea) was used for apoptotic analysis. After $24 \mathrm{~h}$ incubation, cells were trypsinized, washed with $0.5 \mathrm{ml}$ of cold DPBS, and suspended with $0.5 \mathrm{ml}$ by cold $1 \times$ binding buffer. Then, $1.25 \mu \mathrm{l}$ of Annexin V-FITC $(0.5 \mu \mathrm{g} / \mathrm{ml})$ were added and incubated for $15 \mathrm{~min}$ at room temperature in the dark condition. Cells were 
washed and stained with $10 \mu \mathrm{l} \mathrm{PI}(0.3 \mu \mathrm{g} / \mu \mathrm{l})$ or $5 \mu \mathrm{l} 7-\mathrm{AAD}$ (51-68981E, BD Biosciences, San Jose, CA, USA), and observed by fluorescent microscopy (Ti-U, Nikon) and flow cytometry (BD FACSVerse, BD Biosciences).

MMP $\left(\Delta \psi_{\mathrm{m}}\right)$ analysis. MMP of cells were detected by using MitoProbe JC-1 assay kit for flow cytometry (M34152, Molecular Probes) after $24 \mathrm{~h}$ incubation. Cells were resuspened in $1 \mathrm{ml}$ media containing of $\mathrm{JC}-1$ dye $(2 \mu \mathrm{M})$, and incubated at $37{ }^{\circ} \mathrm{C}, 5 \% \mathrm{CO}_{2}$ for $40 \mathrm{~min}$. After washing with $500 \mu \mathrm{l}$ of PBS, the samples were analyzed by using flow cytometry. Before harvesting cells, we added $1 \mu \mathrm{l}$ of $50 \mathrm{mM}$ cccp, and incubated for $10 \mathrm{~min}$ at $37^{\circ} \mathrm{C}$ for a positive control.

Statistical analysis. All values are represented by the mean \pm S.D. of the indicated number of replicates. Statistical analyses of the data were performed using student's $t$-test to establish significance between data points, and significant differences have been based on the $P<0.05$ or $P<0.01$.

\section{Conflict of Interest}

The authors declare no conflict of interest.

Acknowledgements. This work was supported from the National Research Foundation (NRF) of Korea Grant funded by the Korean Government (No. 2010-0027963) and (No. 2012-019866), and partially by Kwangwoon University.

1. Pelicano H, Carney D, Huang P. ROS stress in cancer cells and therapeutic implications. Drug Resist Updates 2004; 7: 97-110.

2. Trachootham D, Zhou Y, Zhang H, Demisu Y, Chen Z, Pelicano $\mathrm{H}$ et al. Selective killing of oncogenically transformed cells through a ROS-mediated mechanism by $\beta$-phenylethyl isothiocyanate. Cancer Cell 2006; 10: 241-252.

3. Shyu K, Huang S, Kuo H, Cheng W, Lin Y. Antitumor activity of a novel bis-aziridinylnaphthoquinone (AZ4) mediating cell cycle arrest and apoptosis in non-small cell lung cancer cell line NCl-H460. Acta Pharmacol Sin 2007; 28: 559-566.

4. Keidar M, Walk R, Shashurin A, Srinivasan P, Sandler A, Dasgupta S et al. Cold plasma selectivity and the possibility of a paradigm shift in cancer therapy. Br J Cancer 2011; 105 : 1295-1301.

5. Dobrynin D, Fridman G, Friedman G, Fridman A. Physical and biological mechanisms of direct plasma interaction with living tissue. N J Phys 2009; 11: 115020.

6. Kalghatgi S, Kelly CM, Cerchar E, Torabi B, Alekseev O, Fridman A et al. Effects of non-thermal plasma on mammalian cells. PLOS ONE 2011; 6: e16270.

7. Baik KY, Kim YH, Ryu YH, Kwon HS, Park G, Uhm HS et al. Feeding-gas effects of plasma jets on Escherichia coli in physiological solutions. Plasma Process Polym 2013; 10 : 235-242.

8. Kaushik NK, Uhm HS, Choi EH. Micronucleus formation induced by dielectric barrier discharge plasma exposure in brain cancer cells. Appl Phys Lett 2012; 100: 084102.

9. Kim GJ, Kim W, Kim KT, Lee JK. DNA damage and mitochondria dysfunction in cell apoptosis induced by nonthermal air plasma. Appl Phys Lett 2010; 96: 021502.

10. Kim K, Choi JD, Hong YC, Kim G, Noh EJ, Lee JS et al. Atmopheric-pressure plasma-jet from micronozzle array and its biological effects on living cells for cancer therapy. Appl Phys Lett 2011; 98: 073701.

11. Ahn HJ, Kim Kl, Kim G, Moon E, Yang SS, Lee JS. Atmospheric-pressure plasma jet induces apoptosis involving mitochondria via generation of free radicals. PLOS ONE 2011; 6: e28154.

12. Gweon B, Kim M, Kim DB, Kim D, Kim H, Jung H et al. Differential responses of human liver cancer and normal cells to atmospheric pressure plasma. Appl Phys Lett 2011; 99: 063701.

13. Panngom K, Baik KY, Ryu YH, Uhm HS, Choi EH. Differential responses of cancer cell lines to non-thermal plasma from dielectric barrier discharge. Curr Appl Phys 2013; 13: S6-S11.
14. Olie RA, Simoes-Wust AP, Baumann B, Leech SH, Fabbro D, Stahel RA et al. A novel antisense oligonucleotide targeting surviving expression induces apoptosis and sensitizes lung cancer cells to chemotherapy. Cancer Res 2000; 60: 2805-2809.

15. Navab R, Strumpf D, Bandarchi B, Zhu C, Pintilie M, Ramnarine VR et al. Prognostic gene-expression signature of carcinoma associated fibroblasts in non-small cell lung cancer. Proc Natl Acad Sci USA 2011; 108: 7160-7165.

16. Leech SH, Olie RA, Gautschi O, Simose-Wust AP, Tschopp S, Haner R et al. Induction of apoptosis in lung-cancer cells following bcl-xL anti-sense treatment. Int J Cancer 2000; 86: 570-576.

17. Kim JY, Wei Y, Li J, Kim S. $15 \mu \mathrm{m}$ sized single-cellular level and cell manipulatable microplasma jet in cancer therapies. Biosens Bioelectron 2010; 26: 555-559.

18. Detmer SA, Chan DC. Functions and dysfunction of mitochondrial dynamic. Nat Rev Mol Cell Bio 2007; 8: 870-879.

19. Liesa M, Palacín M, Zorzano A. Mitochondrial dynamics in mammalian health and disease. Physiol Rev 2009; 89: 799-845.

20. Bernas T, Dobrucki J. Mitochondrial and non-mitochondrial reduction of MTT: Interaction of MTT with TMRE, JC-1, and NAO mitochondrial fluorescent probes. Cytrometry 2002; 47: 236-242.

21. Chen G, Wang F, Trachootham D, Huang P. Preferential killing of cancer cells with mitochondrial dysfunction by natural compounds. Mitochondrion 2011; 10: 614-612.

22. Gogvadze V, Orrenius S, Zhivotovsky B. Mitochondria in cancer cells: what is so special about them? Trends Cell Biol 2008; 18: 165-173.

23. Xu R, Pelicano H, Zhou Y, Carew JS, Feng L, Bhalla KN et al. Inhibition of glycolysis in cancer cells: A novel strategy to overcome drug resistance associated with mitochondrial respiratory defect and hypoxia. Cancer Res 2005; 65: 613-621.

24. Gilkerson RW, Margineantu DH, Capaldi RA, Selker JML. Mitochondrial DNA depletion causes morphological changes in the mitochondrial reticulum of cultured human cells. FEBS Lett 2000; 474: 1-4.

25. Barbieri E, Battistelli M, Casadei L, Vallorani L, Piccoli G, Guescini M et al. Morphofunctional and biochemical approaches for studying mitochondrial changes during myoblasts differentiation. J Aging Res 2011; 2011: 845379.

26. Yan X, Xiong Z, Zou F, Zhao S, Lu X, Yang G et al. Plasma-induced death of HepG2 cancer cells: intracellular effects of reactive species. Plasma Process Polym 2012; 9: 59-66.

27. Joshi SG, Cooper M, Yost A, Paff M, Erca UK. Nonthermal dielectric-barrier discharge plasma-induced inactivation involves oxidative DNA damage and membrane lipid peroxidation in Escherichia coli. Antimicrob Agents Ch 2011; 55: 1053-1062.

28. Su WP, Lo YC, Yan JJ, Liao IC, Tsai PJ, Wang HC et al. Mitochondrial uncoupling protein 2 regulates the effects of paclitaxel on Stat3 activation and cellular survival in lung cancer cells. Carcinogenesis 2012; 33: 2065-2075.

29. Hoentsch M, Woedtke T, Weltmann KD, Nebe JB. Time-dependent effects of low temperature atmospheric pressure argon plasma on epithelial cell attachment, viability and tight junction formation in vitro. Appl Phys 2012; 45: 025206.

30. Fan TJ, Han LH, Cong RS, Liang J. Caspase family proteases and apoptosis. Acta Biochim Biophys Sin 2005; 37: 719-727.

31. Fridman JS, Lowe SW. Control of apoptosis by p53. Oncogene 2003; 22: 9030-9040.

32. Gottlleb E, Armour SM, Harris MH, Thompson CB. Mitochondria membrane potential regulates matrix configuration and cytochrome c release during apoptosis. Cell Death Differ 2003; 10: 709-717.

33. Satoh T, Enokido Y, Aoshima H, Uchiyama Y, Hatanaka H. Changes in mitochondrial membrane potential during oxidative stress-induced apoptosis in PC12 Cells. J Neurosci Res 1997; 50: 413-420.

34. Huang KT, Chen YH, Walker AM. Inaccuracies in MTS assays: major distorting effects of medium, serum albumin, and fatty acids. Biotechniques 2004; 37: 406-412.

35. Wang P, Henning SM, Heber D. Limitations of MTT and MTS-Based assays for measurement of antiproliferative activity of green tea polyphenols. PLOS One 2010; 5: e10202.

36. Ingber DE, Tensegrity I. Cell structure and hierarchical systems biology. J Cell Sci 2003; 116: 1157-1173.

37. Wang $\mathrm{JH}$, Goldschmidt-Clermont $\mathrm{P}$, Yin FC. Contractility affects stress fiber remodeling and reorientation of endothelial cells subjected to cyclic mechanical stretching. Ann Biomed Eng 2000; 28: 1165-1171.

(i) (-) $\Theta$ Cell Death and Disease is an open-access journal published by Nature Publishing Group. This work is licensed under a Creative Commons Attribution-NonCommercialNoDerivs 3.0 Unported License. To view a copy of this license, visit http://creativecommons.org/licenses/by-nc-nd/3.0/ 